\title{
eCOti
DiAno
}

Revista Mídia e Cotidiano

ISSN: 2178-602X

Artigo Seção Livre

Volume 15, Número 2, maio/ago. de 2021

Submetido em: 17/02/2021

Aprovado em: 27/04/2021

\section{"Transforme-se em você!": corpo, narrativas e subjetividade em anúncios de cosméticos para mulheres}

\section{“Transform into you!": body, narratives and subjectivity in cosmetic ads for women}

\section{“Transformarte en ti!": cuerpo, narrativas y subjetividad en anuncios de cosméticos para mujeres}

\author{
Euler David de SIQUEIRA ${ }^{1}$ \\ Denise da Costa Oliveira SIQUEIRA ${ }^{2}$
}

\begin{abstract}
Resumo
O artigo estuda o fenômeno da subjetivação nas narrativas publicitárias de cosméticos para mulheres da empresa Salon Line. Mobiliza as categorias corpo, gênero, subjetividade e consumo como construções sociais. Trata-se de pesquisa exploratória, um estudo de caso desenvolvido a partir de amostra qualitativa por escolha, orientado por abordagem epistemológica compreensiva. A questão discutida diz respeito a como tais narrativas sugerem que a consumidora se individualize, introjetando, no entanto, uma norma que na realidade é exterior. Resultados preliminares deixam entrever que a suposta autonomia presente na publicidade omite o intricado processo de interiorização de normas exteriores.
\end{abstract}

Palavras-chave: Corpo. Consumo. Subjetividade.

\begin{abstract}
The article aims to study the phenomenon of subjectivity in advertising narratives of cosmetic for women from the company Salon Line. It mobilizes the categories body, gender, subjectivity and consumption as social constructions. This is an exploratory research, a case study developed from a qualitative sample by choice, guided by a comprehensive epistemological approach. The question discussed concerns how such narratives suggest that the consumer individualizes herself, introducing, however, a norm

\footnotetext{
${ }^{1}$ Doutor e mestre em Sociologia pelo IFCS/UFRJ. Desenvolveu estágio de pós-doutorado em Sociologia na Université Paris-Descartes (Capes). Professor Titular da Universidade Federal Rural do Rio de Janeiro e do Programa de Pós-Graduação em Práticas em Desenvolvimento Sustentável. E-mail: euleroiler@gmail.com. ORCID: 0000-0002-0985-6900. na Université de Strasbourg $(\mathrm{CNPq})$. Professora Titular do Programa de Pós-Graduação em Comunicação da Universidade do Estado do Rio de Janeiro. Líder do grupo de pesquisa Corps: corpo, representação e espaço urbano. E-mail: dcos@uerj.br. ORCID: 0000-0001-7501-7390.
}

${ }^{2}$ Doutora em Ciências da Comunicação pela ECA/USP. Desenvolve estágio pós-doutoral em Sociologia
\end{abstract}


that in reality is external. Preliminary results indicate that the supposed autonomy present in advertising omits the complex process of internalizing external norms.

Keywords: Body. Consumption. Subjectivity.

\section{Resumen}

El artículo estudia el fenómeno de la subjetividad en las narrativas publicitarias de cosméticos para mujeres de la empresa Salon Line. Moviliza las categorías cuerpo, género, subjetividad y consumo como construcciones sociales. Esta es una investigación exploratoria, un estudio de caso desarrollado a partir de una muestra cualitativa por elección, guiado por un enfoque epistemológico comprensible. La pregunta discutida se relaciona con cómo tales narrativas sugieren que el consumidor se individualiza, introduciendo, sin embargo, una norma que en realidad es externa. Los resultados iniciales indican que la supuesta autonomía presente en la publicidad omite el complejo proceso de internalización de las normas externas.

Palabras clave: Cuerpo. Consumo. Subjetividad.

\section{Introdução}

O consumo de produtos para corpo e cabelos parece ocupar um lugar tão significativo nas sociedades contemporâneas quanto o do vestuário, da alimentação e da saúde. Para além do aspecto econômico envolvido na produção e venda de cosméticos, seu consumo opera como sinal evidente da importância que o embelezamento do corpo representa nos dias atuais. As diversas mídias e a publicidade reforçam esse lugar de destaque nas práticas sociais cotidianas, nas narrativas e no imaginário.

Cabelos, pelos corporais e produtos a eles destinados ocupam espaço de relevo no campo dos cosméticos. Os significados atribuídos aos pelos e a riqueza simbólica das linguagens da capilaridade evocam representações e classificações sociais, como apontou Bromberger (2015). Juntos, pelos, barbas e cabelos compõem o que o autor denominou de "sistema tricológico", um sistema simbólico, pleno de sentidos, com potencial para significar. Homens barbudos com sobrancelhas e peito depilados são um exemplo desse universo. Pernas e axilas femininas depiladas ou não, cabelos alisados, descoloridos, encrespados e transições capilares carregam muitos sentidos sobre os lugares dos indivíduos na sociedade, seus pertencimentos, distanciamentos e identidades étnicas e de gênero. Em poucas palavras, cabelos e pelos do corpo são bons para pensar, parafraseando Lévi-Strauss (1989), assim como para a construção da identidade. 
Nesse quadro, o corpo e o consumo de produtos para tratamento e embelezamento são frequentemente vistos como assuntos exclusivos do indivíduo moderno (DUMONT, 1993), dono de sua própria vontade, como explícito na fala publicitária da empresa de cosméticos Salon Line: "Nós, da Salon Line, incentivamos você a reinventar a sua personalidade, ou encontrar a sua essência mais profunda e verdadeira, porque a gente sabe que a sua beleza é única! Permita-se e venha com a gente. Transforme-se em você com a Salon Line!"3. Aqui, a busca pela beleza é principalmente da ordem da interioridade - o que afastaria, conforme apregoa a campanha, a identificação com padrões estéticos veiculados pela mídia e nos leva a discutir o jogo entre autonomia e normas sociais. Salon Line se coloca como uma espécie de guru ou mediador capaz de auxiliar o sujeito na busca de sua beleza interior, assinalando, contraditoriamente, a total autonomia do sujeito na tomada de suas decisões.

Algumas pistas importantes para se compreender a importância atribuída ao corpo e ao poder de decisão e escolha do indivíduo moderno, fundamentais no consumo, são encontradas na derrocada das narrativas universalistas assim como na crise do Estado e da modernidade (LYOTARD, 2005). A erosão de instituições âncoras da modernidade como Estado, esfera pública, trabalho, Igreja, família nuclear, abriu espaço para a centralidade do indivíduo como artífice de seu próprio eu, ao mesmo tempo em que situou o consumo e o corpo como formas singulares de expressão.

O destaque dado ao indivíduo como o principal responsável por sua individualidade é, no entanto, contraditório e ambíguo. O consumo individual de cosméticos não significa que o sujeito esteja livre do confronto com forças ou estruturas sociais que também modulam suas decisões. Ao lado dos fenômenos da individualização e do consumo, outra importante influência pesa nas decisões e escolhas dos consumidores: a midiatização. Midiatização aqui entendida como o processo que situa meios e plataformas de comunicação como espaço central na percepção e compreensão da realidade social por parte dos sujeitos. Assim, o quadro de referências posto à disposição dos sujeitos é infinitamente mais amplo do que em qualquer outra época da história. Diante da explosão de vozes e referências (inclusive as midiáticas), escolher se

\footnotetext{
${ }^{3}$ Site da marca. Disponível em: https://salonline.com.br/. Consulta em 26/03/2020.
} 


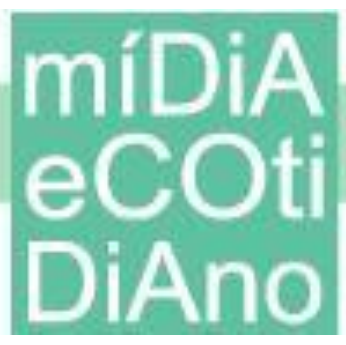

faz necessário. Nesse momento se articulam norma social e individualização, pois que a escolha também é social (VIGARELLO, 2007).

Partindo dessas ideias, o objetivo deste artigo é discutir as narrativas de individualização e de personalização do corpo feminino - notadamente por meio do tratamento dos cabelos - presentes na publicidade da empresa brasileira de cosméticos Salon Line. Sob o emblemático slogan de "Transforme-se em você", a publicidade da empresa paulista focada inicialmente em salões de cabeleireiros, ganha espaço em mídias sociais como YouTube, Instagram e Facebook. As mulheres, público-alvo das campanhas da empresa, são confrontadas a dilemas corporais com repercussões sobre a representação que têm de si mesmas. A publicidade joga com essas inquietações (SIQUEIRA, RIBEIRO, 2012).

Voltada para o tratamento capilar, Salon Line veicula em sua publicidade uma visão de mundo em que a mulher é alçada à personagem principal na construção de sua própria subjetividade. Fabricar sua subjetividade, personalizando seu cabelo com o uso de cosméticos, especialmente no contexto urbano em que o indivíduo é uma das formas elementares da vida social, remete às discussões feitas pelo sociólogo alemão Georg Simmel (2007), em seu texto A metrópole e a vida mental, ao mesmo tempo em que possibilita compreender o lugar do corpo e do consumo como fatores fundamentais no processo de individualização.

Nossa investigação se caracteriza como qualitativa e exploratória. Em termos metodológicos e de recorte, adotamos uma abordagem antropológica relacional (LE BRETON, 2001; LE BRETON, 2010; GEERTZ, 1978), assim como uma perspectiva hermenêutico-interpretativa para ler materiais da campanha publicitária "Transforme-se em você", veiculada a partir de 2017. Dito de outra forma, interpretamos interpretações, como Geertz assinalara em A interpretação das culturas (1978). E conforme sublinha Cecília Minayo, a matriz compreensiva: "privilegia a compreensão e a inteligibilidade como propriedades específicas dos fenômenos sociais, mostrando que o significado e a intencionalidade os separam dos fenômenos naturais" (1992, p.50). Com isso, evitamos a substancialização ou a essencialização a respeito das diferentes formas com que os sujeitos compreendem a realidade social. Afinal, a realidade social não se apresenta aos 


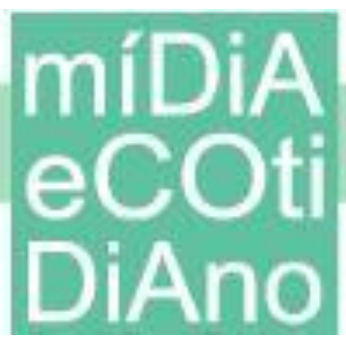

sujeitos de uma maneira direta e objetiva, sendo necessária a presença de um sistema de coordenadas simbólicas para lê-la.

O corpus estudado para a construção deste artigo se constitui do site da marca, de um vídeo postado no Youtube e no Facebook e de dois painéis expostos em estações de metrô do Rio de Janeiro. Não nos detemos na descrição esmiuçada de cada material, mas estudamos ao longo do texto o conjunto da narrativa veiculada. A partir da leitura e do estudo do material empírico, buscamos discutir a problemática de como tais narrativas preconizam que a mulher se individualize, se veja como singular, introjetando, no entanto, uma norma que na realidade é exterior.

Teoricamente, partimos das pistas deixadas pelos pensadores Georges Vigarello (2007; 2010), David Le Breton (2010), Michela Marzano (2010) e Isabelle Queval (2008) para compreender o cuidado e o embelezamento do corpo como expressões do processo histórico mais geral denominado de individualização cuja consolidação é dada pelo processo atual de subjetivação ou de personalização corporal. Não excluímos a relevância de inúmeros outros autores para compreender o fenômeno que nos propomos investigar, mas neste artigo nos interessa discutir a abordagem desses intelectuais acerca do corpo e sua contribuição para os estudos de comunicação.

Individualização e subjetivação remetem ao debate sobre liberdade e autonomia frente às normas sociais impostas por grupos ou estruturas sociais. Não se trata de considerar neste texto a ideia de indivíduos autônomos escapando a toda e qualquer regra ou norma social. Trata-se de refletir sobre a forma como a norma ou a regra exterior é subjetivada e apropriada pelo sujeito que faz dela uma forma de conhecimento de si próprio (QUEVAL, 2008).

O texto tem início com a discussão sobre a importância simbólica e cultural do corpo na contemporaneidade e sua relação com o processo de individualização. Em seguida, tratamos do intricado jogo simbólico armado entre consumo e incorporação dos signos supostamente presentes nos cosméticos. Finalmente, mostramos que a publicidade veiculada por Salon Line oferece um valioso suporte ao processo de subjetivação da norma social exterior notadamente por meio de suas narrativas de aconselhamento.

Ao trazer uma reflexão sobre um tipo de narrativa publicitária que oferece beleza ao corpo feminino por meio de uma linha de produtos para cabelo, este artigo aponta para 


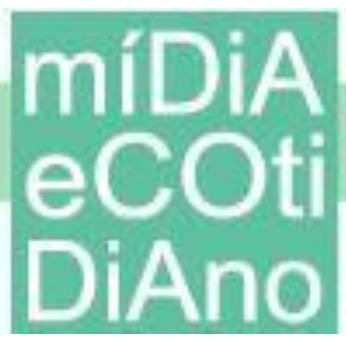

um tipo de discurso que promove a valorização da consumidora mas, paralelamente a responsabiliza, deslocando aspectos sociais para um campo individual. A campanha estudada localiza a beleza em um espaço individual, subjetivo, quando se observa que a fabricação da beleza é um processo social e coletivo. A temática desenvolvida e a questão levantada sinalizam a relevância dos estudos sobre corpo e suas narrativas para o campo de estudos sobre mídia e cotidiano. Afinal, trata-se de articular narrativas veiculadas midiaticamente à vida banal, cotidiana, mas também a imaginários sensíveis, a jogos de aparência, enfim, a rituais.

\section{Corpo, cosmético e individualização}

O corpo ocupa hoje papel de destaque nas culturas midiatizadas. Reproduzido, reformado, transformado, expõe subjetividades e coletividades. Detrez argumenta que a liberação do corpo, no entanto, não significa o fim das obrigações sociais ou morais: "Podemos sublinhar o paradoxo de uma liberação do corpo cujo modelo passa somente pela restrição, o esforço e a perpétua vigilância de si e de sua alimentação" (2002, p.203). Desse modo, se diminuem ou cessam os constrangimentos morais de ordem exterior, cabe ao próprio sujeito toda a responsabilidade. A norma objetiva, exterior, é então subjetivada (DETREZ, 2002). Nessa perspectiva, o individualismo não significaria, como poderia parecer, um fenômeno menos social, como explicou Simmel (2007).

O discurso veiculado por Salon Line opera por meio de sugestão sem cair na prescrição impositiva: "Existimos para encorajar o novo, a descoberta e a mudança. Acreditamos que cada pessoa pode ser o que quiser e é por isso que incentivamos você a

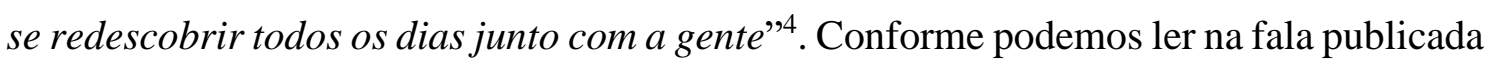
no site da empresa, Salon Line convida e encoraja as mulheres - com destaque para as negras e de cabelos crespos, como as imagens dão a ver e uma campanha de $2019^{5}$ reforça - a empreender a busca diária por sua verdadeira beleza interior. A redescoberta de si não

\footnotetext{
${ }^{4}$ Site da marca. Disponível em: https://salonline.com.br/. Consulta em 26/03/2020.

5 Para maiores informações: Comercial da Salon Line celebra força de mulheres negras. Uol, 04/09/2019, disponível em: https://economia.uol.com.br/noticias/redacao/2019/09/04/comercial-da-salon-linecelebra-forca-de-mulheres-negras.htm. Consulta em 05/04/2020. E: Salon Line tem campanha 100\% produzida por profissionais negros. Meio e mensagem, 02/02/09/2019, disponível em: https://www.meioemensagem.com.br/home/comunicacao/2019/09/02/salon-line-tem-campanha-100produzida-por-profissionais-negros.html. Consulta em 05/04/2020.
} 
é, contudo, simples - trata-se de um processo diário que não precisa ser vivido solitariamente, podendo ser acompanhado pela empresa sob a forma de seus produtos. Os produtos de Salon Line são, então, a materialização de categorias culturais que tornam socialmente existentes os sujeitos sociais.

Em Le corps aujourd'hui, Queval assinala que "o corpo é o que resta quando tudo está perdido" (2008). A ela junta-se Marzano, para quem o corpo é um ponto de convergência de diferentes interesses em que se "acumula toda uma série de práticas e discursos" (2012, p.13). Detrez, por sua vez, sublinha que o corpo é alvo de discursos, políticas e regimes morais cujo único propósito parece ser seu controle: “o corpo, mesmo liberado de suas roupas, mesmo nu (...) não deve ser, sobretudo, animal: luta contra a flacidez, contra a moleza, contra o desleixo, corpo liso e depilado, bronzeado e musculoso, nova norma do corpo livre" (2002, p.202).

Não se trata de bradar a conquista absoluta da liberdade individual assim como o fim dos regramentos morais, das coerções e das obrigações sociais. Vigarello aponta que, a despeito de tudo que o sujeito moderno possa fazer, ele não pode deixar de escolher. As escolhas e decisões a seu cargo alcançam níveis inimagináveis e não escondem por completo o quadro restritivo e coercitivo cuja interiorização, ou ainda, a subjetivação da norma exterior, representa um fardo tão ou mais pesado que o anterior (VIGARELLO, 2007). E grande parte das narrativas contemporâneas sublinha que cabe unicamente ao sujeito decidir. O sujeito moderno e suas escolhas são, entretanto, eles mesmos categorias sociais.

A teoria aqui mobilizada permite compreender que, a despeito do discurso pretensamente centrado na autonomia do sujeito, traduzido sob a forma de suas escolhas, estamos diante de um fato social que exerce forte constrangimento sobre o modo como os sujeitos fazem suas escolhas. Como asseveram Le Breton e Vigarello, a interiorização da norma exterior não significa um levantamento das coerções ou dos constrangimentos. Ao contrário, interiorizada ou subjetivada, a norma exterior se faz presente na forma como o próprio sujeito controla a si. Por outro lado, não é o consumo do produto ou suas propriedades que libertam ou dão autonomia, mas principalmente o reforço da sugestão de buscar conhecer-se a si próprio. A publicidade observada constitui, na realidade, uma narrativa sobre a agência da consumidora fabricada a partir de normas exteriores. 
O arsenal de modificações corporais hoje à disposição de mulheres, homens, LGBTQI+ é vasto e não para de crescer. Aos recursos da medicina e da cirurgia, da farmacologia, aos regimes alimentares e dietas variadas, às práticas esportivas e de ginástica, somam-se produtos cosméticos de embelezamento cuja magia faz apelo às narrativas midiáticas (SIQUEIRA, 2019). Assim, shampoos, condicionadores, cremes, tinturas prometem, por meio da ciência e não menos da magia, saúde, vigor, força, nutrição, regeneração, brilho, maciez, volume. Além de atributos estéticos visíveis, os cosméticos prometem algo mais sintomático de nossa época: o reencontro do sujeito consigo mesmo. Fazendo subjetiva a norma exterior, promove-se o encontro da regra com a intimidade. A esse respeito, sublinha Queval, “a oferta cosmética e cirúrgica em evolução constante responde a chamada a um melhor conhecimento de si, a uma compreensão dos funcionamentos internos do corpo" (2008, p.140).

Desse modo, o discurso cosmético prega que o eu íntimo deve se expressar sem receio por meio de um processo performativo de conhecimento de si. Trata-se da possibilidade de o indivíduo (re)conhecer a si próprio sem se sentir refém de outras identidades atribuídas a ele. Elixir contra a alienação ou contra as crises de identidade, os valores colados aos cosméticos colocam diante de cada sujeito a possibilidade de (re)conhecer o seu "verdadeiro eu". No caso da publicidade de Salon Line, fica implícita a fala sobre a beleza da mulher negra brasileira - embora os textos não façam referência à raça, as imagens do site da empresa costumam mostrar uma mulher branca e várias mulheres negras de diferentes tons de pele e de diversas texturas de cabelo. Há, na realidade, uma escala de texturas de cabelos: liso, ondulado, cacheado, crespo, crespíssimo. Essa classificação ordena os produtos oferecidos para cada tipo de beleza - cabe à consumidora se identificar com uma das categorias, o que reforça a ideia de escolha e autonomia.

O destaque que o corpo conquistou nas últimas décadas foi decisivo para isso. Historicamente situado no polo inferior da oposição com a alma, o corpo passou por importantes mutações sociais e culturais responsáveis por seu deslocamento para o centro da cena contemporânea. Antes menosprezado e negado reiteradamente no universo dos fatos sociais pela sociologia nascente, em grande parte devido a sua identificação com as ciências biológicas (DURKHEIM, 1996), seu retorno triunfal nas últimas décadas porta concretude máxima e permite aos sujeitos um leque vasto de possibilidades. Muitos são 


\section{míDiA

os analistas sociais que afirmam não ser mais possível compreender fenômenos centrais da vida social contemporânea como a individualização, o consumo e o gênero sem considerar o corpo como mediador singular entre o sujeito e o mundo (VIGARELLO, 2007; LE BRETON, 2010; MARZANO, 2010; QUEVAL, 2008).

O corpo feminino e o corpo feminino negro, em especial, se valorizam nos espaços midiáticos. A mulher negra foi por muito tempo invisibilizada na publicidade. A predominância de corpos brancos, masculinos e heteronormativos nas imagens midiáticas revelou a mulher negra em um lugar de enorme desvantagem na sociedade. Carneiro observa que

os meios de comunicação não apenas repassam as representações sociais sedimentadas no imaginário social, mas também se instituem como agentes que operam, constroem e reconstroem no interior da sua lógica de produção os sistemas de representação (...), eles ocupam posição central na cristalização de imagens e sentidos sobre a mulher negra (2003, p.125).

Em um mundo em que as mudanças sociais, políticas e econômicas, cada vez mais velozes, parecem apagar as referências identitárias antes sólidas que guiavam a vida social, o corpo, ignorado e inferiorizado durante séculos, torna-se expressão do individualismo contemporâneo (VIGARELLO, 2007; LE BRETON, 2010; DETREZ, 2002, MARZANO, 2010). O corpo não é um dado natural a partir do qual a sociedade e a cultura viriam inscrever suas normas, regras e determinações. A ideia do corpo como organismo biológico anterior à sociedade ou à linguagem é uma construção social própria do Ocidente. A oposição natureza-cultura toma a natureza como um dado enquanto tratase ela mesma, a natureza, de uma categoria culturalmente construída. É frequente a confusão entre a unidade biológica da espécie com o indivíduo moderno ou moral. Enquanto o primeiro existe em toda e qualquer sociedade, o segundo é uma construção social cuja emergência somente foi possível no Ocidente no século XVI (FOUCAULT, 1976; DUMONT, 1993).

No controle do corpo e do sujeito, o consumo de cosméticos abre um vasto campo de possibilidades. Entretanto, o uso de cosméticos não é recente como também não se restringe ao Ocidente. Em diferentes civilizações há relatos do uso de substâncias 
aplicadas ao rosto e que respondiam a diferentes fins, entre eles o estético. Egípcios, gregos e romanos da Antiguidade, assim como os asiáticos, os utilizavam frequentemente. Contudo, nada se parece com a dimensão que o fenômeno teve no Ocidente. Conforme assinala a pesquisadora Catherine Lanoë: "que eles ganhem lugar no quadro dos usos sagrados ou profanos, o gosto pelo enfeite e a vontade de embelezar o corpo são traços constantes das sociedades humanas" (2013, p.17).

A utilização de cosméticos para mudança de aparência é testemunha do aprofundamento do individualismo moderno, processo histórico-social iniciado no século XVI e que até hoje demonstra sua envergadura. Em Le corps féminin, Perrot destaca que o corpo é transformado e alterado das mais diversas formas ao mudar sua aparência (1991). Georges Vigarello (2007, p.238) sublinha as mudanças que o corpo sofreu ao longo dos séculos na Europa tendo os cosméticos assumido um importante papel nesse processo. Ainda de acordo com o autor, as razões da explosão do embelezamento não se esgotam no consumo e nas ideologias da escolha.

O fato de o indivíduo ser responsável por suas escolhas e decisões não significa a ausência de constrangimentos e restrições sociais ou morais. As restrições, antes exteriores, internalizam-se e implicam pressões: "a grande sociedade não diz mais a ninguém o que deve ser. As instituições não governam mais o penteado e a roupa como fizeram durante tanto tempo os ofícios, as geografias, as comunidades" (VIGARELLO,2007, p.238). Certamente, a sociedade à qual faz referência Vigarello não determina mais o que e como se vestir, mas muitas outras vozes fornecem pistas para que os consumidores operem suas escolhas, entre elas a publicidade. David Le Breton faz coro com Vigarello ao destacar a individualização do corpo e a importância que os cosméticos tiveram nesse processo: "vivemos a individualização do sentido e, simultaneamente, uma individualização do corpo. Um formidável mercado da cosmética, do design corporal se desenvolve propondo incontáveis ateliers de transformação do corpo. Mudando seu corpo, o indivíduo deseja mudar sua existência” (2010, p.107).

Queval também sublinha a importância do sujeito e da dupla articulação entre o interior e o exterior, entre intimidade e aparência: "O mérito de uma beleza trabalhada torna-se benefício dessa colaboração entre o sujeito e a ciência, entre a interioridade e a exterioridade, entre o íntimo e os códigos" (2008, p.140). O uso de produtos cosméticos 


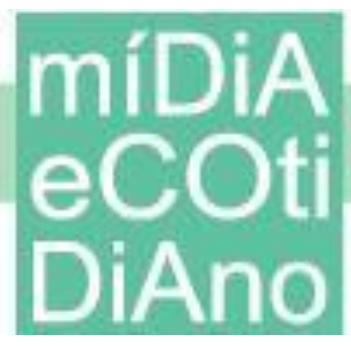

para tratamento de cabelos ou do corpo não se esgota nos efeitos perceptíveis, mas também corresponde a uma mudança interna e subjetiva do indivíduo: mudanças na aparência implicariam mudanças internas.

\section{Consumo, incorporação e identidade}

Para Rocha, o consumo é "um dos grandes inventores da ordem da cultura em nosso tempo, expressando princípios, categorias, ideais, estilos de vida, identidades sociais e projetos coletivos" (ROCHA, 1996, p.55). Consumir é um ato de classificação e ordenação, de atribuição de sentidos e significados às coisas, aos objetos e aos serviços. Nesse sentido, se fundamenta em princípios classificatórios, linguagens simbólicas, enfim, cria cultura. É dessa forma que "o consumo, visto no horizonte das trocas simbólicas, e não apenas na perspectiva das reações subjetivas, amplifica o horizonte interpretativo, significando um passo além dos reducionismos implícitos na discussão psicológica generalista de um consumidor singularizado" (ROCHA, 1996, p.55).

Barbosa, da mesma forma, chama a atenção para como as contribuições de uma antropologia do consumo permitem entender o consumo como um mediador e não apenas algo com um fim em si mesmo - a posse de um objeto. Consumo se articula com a construção de novas identidades, a diferenciação social, a luta por posição social, o prazer íntimo, a expressão de visões particulares de mundo, a resistência cultural e muito mais (BARBOSA, 2003, p.43).

O consumo opera como ponte que conecta o consumidor a inúmeras outras esferas sociais e de significados plurais. Para Rocha, caberia notadamente à publicidade operar a relação entre dois mundos dicotômicos, o da produção e o do consumo, como faz o totemismo quando opera a relação natureza x cultura: “como 'operador totêmico', a publicidade promove a aliança pela complementaridade que estabelece entre produtos e pessoas. Os produtos antes indiferenciados são aliados aos 'nomes', 'identidades', 'situações sociais', 'emoções', 'estilos de vida', 'paisagens', dentro dos anúncios" (ROCHA, 1985, p.106).

Ao articular e complementar os universos da produção e do consumo, a publicidade de Salon Line permite que os sujeitos se orientem a partir da classificação simbólica que atribui a substâncias químicas propriedades mágicas cujo efeito ultrapassa 


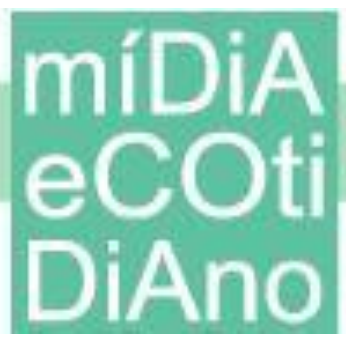

as transformações aparentes. A publicidade de Salon Line não diz explicitamente a seu público o que consumir, ainda que seu objetivo comercial seja efetuar vendas. Não se trata de um discurso impositivo ou diretivo sustentado por aspectos econômicos, medicinais ou científicos. Salon Line insiste no processo de autodescoberta e de identificação do sujeito consigo mesmo, como mostra trecho da fala do comercial da marca: "Você é única. Você é muitas. Você é cada beijo, abraço, selfie, like. É dúvida e é certeza. A curva e a reta. Você é a força que te faz mudar e descobrir quem você é para mudar tudo de novo". ${ }^{6}$ Nas narrativas de Salon Line cabem todos os tipos de corpos, cabelos e rostos. Trata-se de fabricar sua própria individualidade e subjetividade descobrindo-se para além de supostas imposições sociais coercitivas. Nesse sentido, normas e forças sociais não são postas de lado, mas internalizam-se.

O consumo é de tal forma central em nossas vidas a ponto de observarmos o quanto se mostra decisivo na constituição dos grupos sociais e da individualidade. Ele é fundamental no processo de individualização. Conforme assinala Heilbrunn, "queiramos ou não, vivemos em uma sociedade de consumo, isto é, em uma sociedade que consagra às práticas de consumo uma importância fundadora do sentido, do valor e da finalidade da existência de seus membros" (2005, p.7). Em linhas gerais, diversos autores concordam que o consumo não é uma resposta a qualquer tipo de necessidade natural inata.

Como muitas outras categorias, a de consumo é ambígua e repleta de malentendidos. Se hoje o termo consumo não parece despertar a atenção daqueles que o animam todos os dias por meio de suas práticas, não significa que seja banalizado. Como mostra Heilbrunn (2005), o termo aparece etimologicamente associado à ideia de destruição, quando, por exemplo, alguma coisa é consumida pela ferrugem ou por um incêndio. Além do sentido (negativo) de destruição, a noção de consumo possui outros, sendo um dos mais comuns a ideia de aquisição ou posse.

Os cosméticos produzidos por Salon Line constituem um tipo de produto cujo consumo implica a participação ativa do consumidor. Para Salon Line, a aparência não revela quem a pessoa é verdadeiramente. Fazendo uso dos produtos da marca a

\footnotetext{
${ }^{6}$ Trecho de comercial de 45 segundos da campanha publicado em 10/11/2017. Disponível no YouTube em: https://www.youtube.com/watch?v=tIC6e3EpIrY. Acesso em 21/03/2020. Na ocasião, o comercial havia sido visto mais do que 12 milhões de vezes.
} 


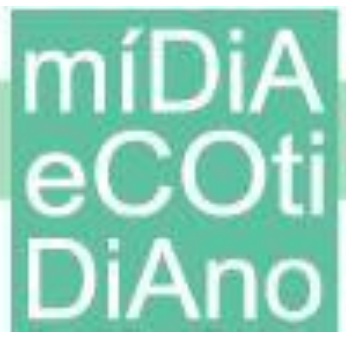

consumidora é auxiliada a transformar-se em si mesma em um processo que vai do interior até o exterior: "Cada pessoa não é apenas aquilo que aparenta ser, ninguém nasce pronta, portanto, o nosso objetivo é facilitar cada uma das mudanças diárias, desde o interior, até o último fio de cabelo. Afinal, nada mais fácil do que se transformar todos os dias junto com quem entende do seu cabelo, da sua pele e de todas as características que te fazem única, não é mesmo!?"' . Cabelo, pele e outras partes do corpo fazem de cada pessoa um ser único. Contudo, as mulheres podem não se conhecer totalmente. Elas poderiam confundir-se com padrões e modelos estéticos que impediriam o conhecimento de sua beleza. Caberia à Salon Line o papel de conduzir a consumidora em busca de sua verdadeira beleza - que se confunde com seu verdadeiro eu.

Ao se fazer uso de um produto de Salon Line, não é apenas a química que se está consumindo, mas a promessa que ela traz de transformação e felicidade. A esse respeito, assinala Isabelle Queval: "Pois que a psicologização das condutas assinala ao mesmo tempo sua apropriação e sua responsabilização, o sujeito livre de sua beleza é também o seu promotor" (2008, p.140). Assim, ao mesmo tempo em que utiliza cosméticos, o sujeito passa a ser responsabilizado pelas consequências desse uso.

Os produtos Salon Line requerem uso regular. Trata-se de um uso que articula ao menos dois processos simbólicos complementares: o produto, de uso externo, é aplicado sobre os cabelos. Tem-se, então, um efeito do exterior para o interior. $\mathrm{O}$ efeito do produto sobre os cabelos desencadeia um segundo processo, cujo efeito é o de abrir caminho para que a consumidora possa exprimir seu verdadeiro eu por meio do conhecimento de si. Trata-se fundamentalmente de um processo de incorporação que implica um tempo que pode ser mais ou menos longo. A incorporação das qualidades ou atributos veiculados por Salon Line é ambígua, afinal, o produto sugere que o sujeito se transformará nele mesmo e não em outra pessoa, como uma celebridade, por exemplo "Transforme-se em você", anuncia o slogan da campanha, no modo imperativo.

A incorporação das propriedades dos cosméticos produzidos pela marca não opera necessariamente transformando a intimidade, mas, liberando-a. Os produtos agiriam externamente, permitindo que a intimidade se exteriorizasse sem obstáculos de

\footnotetext{
${ }^{7}$ Site da marca. Disponível em: https://salonline.com.br/. Consulta em 26/03/2020.
} 


\section{míDiA

quaisquer ordens. Ao modificar o cabelo e a aparência das mulheres, os cosméticos de Salon Line realizariam uma espécie de alinhamento entre a imagem real do sujeito e a imagem ideal, ao mesmo tempo em que ignorariam a imagem de como os outros o veem. Assim, como aponta Heilbrunn, "o consumo simbólico significa que o indivíduo procura frequentemente melhorar a imagem de si por meio do consumo de bens e de símbolos. $\mathrm{O}$ conceito de si é melhorado por meio da transferência de significações aceitas socialmente do produto ou da marca para a pessoa" (2005, p.99).

\section{Cuide do que é seu: transforme-se em você!}

A campanha de Salon Line faz parte de uma estratégia iniciada em 2016 e divulgada nas redes sociais - onde a empresa faz um trabalho intenso por meio de agências de publicidade, de embaixadoras e influenciadoras digitais ${ }^{8}$ - mas também em mobiliário urbano (cartazes eletrônicos no metrô, busdoors, painéis em relógios digitais de rua). Algumas de suas peças ocuparam displays eletrônicos das estações de metrô do Rio de Janeiro. Selecionamos duas dessas peças para apresentar neste texto - ambas expostas em importantes estações de metrô, lugares de confluência urbana: de ruas, pessoas, rico comércio em lojas e ambulantes, espaços religiosos e transporte público (onde metrô e ônibus se integram). Largo da Carioca e Largo do Machado são lugares de passagem, contraste social, alta (in)visibilidade, tráfego intenso e circulação densa de trabalhadoras de estratos sociais diversos.

A primeira peça, um cartaz eletrônico, ocupou um display da estação do metrô do Largo da Carioca, no Centro do Rio. A peça exibia a imagem de uma jovem, branca, de cabelos lisos, sorridente e com os seguintes dizeres: "Perfeito para quem tem os cabelos e as vontades bem claras. Meu liso. Do que é meu cuido eu. Transforme-se em você". Assim, a empresa brasileira de cosméticos se dirige a seu público em anúncios na Internet e em telas espalhadas pela cidade. Mais do que um simples slogan, a palavra é reveladora da centralidade que o corpo e a subjetividade assumem na fabricação da individualidade contemporânea.

\footnotetext{
${ }^{8}$ Salon Line lança sua primeira campanha publicitária. Grandes nomes da propaganda, 14 de dezembro de 2016. Disponível em: https://grandesnomesdapropaganda.com.br/anunciantes/salon-line-lanca-suaprimeira-campanha-publicitaria/. Acesso em: 02/04/2020.
} 
Figura 1 - Anúncio em estação de metrô

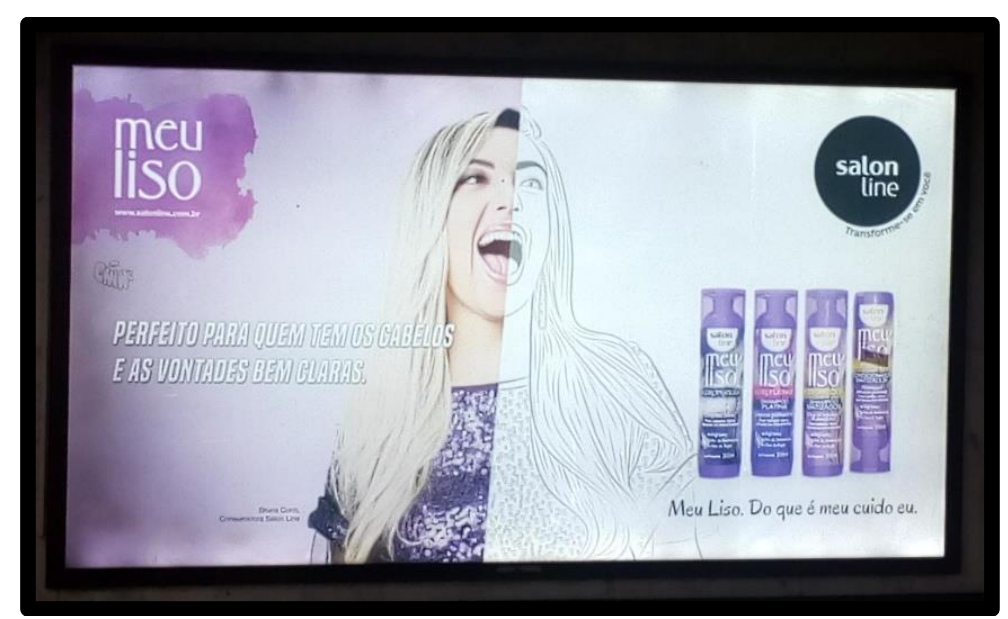

Fonte: Foto dos autores.

Transformar-se em si mesmo não é uma expressão evidente. Ela revela diferentes mutações sociais cujos efeitos situam o corpo e a individualidade como fenômenos fundamentais na contemporaneidade (VIGARELLO, 2007; LE BRETON, 2010; MARZANO, 2010). Um dos aspectos mais relevantes na ideia de transformar-se em si mesmo é o que assinala o fato de que para identificar-se consigo próprio o outro não parece ser levado em consideração. O “eu vitrine”, a imagem que acreditamos que os outros têm de nós mesmos, seria deslocada para um plano secundário - pensamento veiculado pelo tipo de publicidade estudada.

No discurso de Salon Line, o eu pessoal é dado de antemão, bastando que o sujeito se desembarace de referências exteriores - o eu ideal e o eu vitrine, frequentemente sociais ou coletivos - que não correspondem ao que de fato o sujeito é. Nesse sentido, Salon Line aponta para uma forte naturalização do sujeito e do corpo - ainda que ambiguamente aponte para uma perspectiva de construção. Evidentemente, para se transformar em si mesmas, as consumidoras contam com a ajuda de uma vasta gama de cremes, shampoos, condicionadores e preciosos conselhos de autoajuda.

Outra frase da narrativa veiculada no display da estação de metrô é: "Do que é meu, cuido eu”. Nessa frase o sujeito é alçado à condição de senhor de seu corpo, identificando-se com ele em todos os aspectos. A sentença remete à ideia de cuidado consigo mesmo. Ainda se destaca nessa fala a ideia de que o corpo e sua subjetividade 


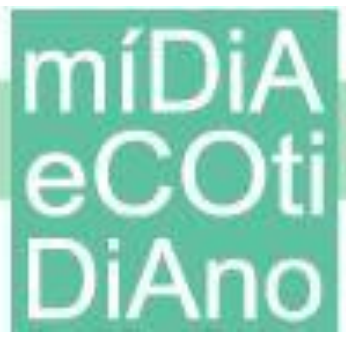

constituem valiosos capitais não necessariamente conhecidos ou suficientemente cultivados, mas que podem ser explorados ou desenvolvidos com a ajuda de cosméticos. A subjetividade, nesses termos, implicaria um processo de autoconhecimento e descoberta gradual. Ganha força aqui a ideia de liberdade de escolha, um atributo fundamental constituinte da noção moderna de sujeito (DUMONT, 1993; VIGARELLO, 2007).

A segunda peça que destacamos também foi vista no metrô, na estação do Largo do Machado, no bairro do Catete, na Zona Sul da cidade. A peça mostra a imagem de uma jovem negra, maquiada, de cabelos cacheados. Ao lado de sua foto podemos ler a seguinte frase iniciada com uma hashtag: "\#tôdecacho. Esse mundo é meu. Um mundo onde meu cabelo é só meu cabelo”. A narrativa veiculada por Salon Line nessa publicidade mais uma vez coloca em destaque o sujeito, sendo o cabelo "cacheado" um fator importante na construção de sua identidade pessoal. A valorização do cabelo cacheado ou crespo é acompanhada da ideia de individualidade e singularidade: há muitos tipos de cacho, mas um que é só da personagem e de mais ninguém. Essa fala acentua a individualidade, situando o cabelo como princípio de subjetivação (QUEVAL, 2008). Um site exclusivo para o cabelo cacheado foi criado por Salon Line. Nesse site encontramos produtos, processos e depoimentos de pessoas que passaram a se valorizar a partir do momento em que aceitaram não somente seu tipo de cabelo mas também seu corpo.

Figura 2 - Anúncio em estação de metrô

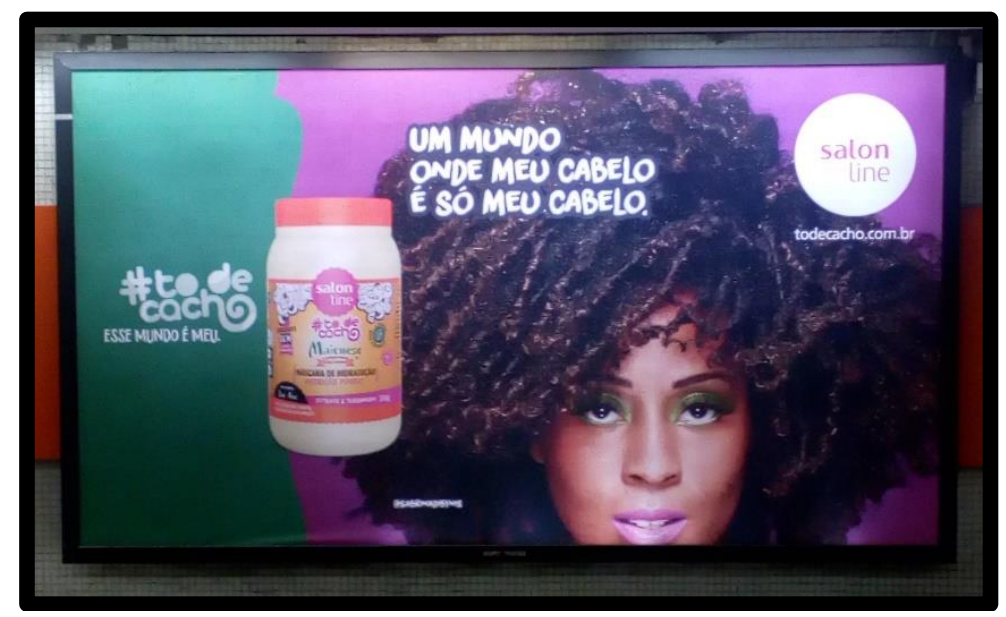

Fonte: Foto dos autores.

O cabelo é a parte do corpo que constitui alvo principal da publicidade de Salon

Line, possuindo características interessantes e que requerem, por parte do sujeito, uma 


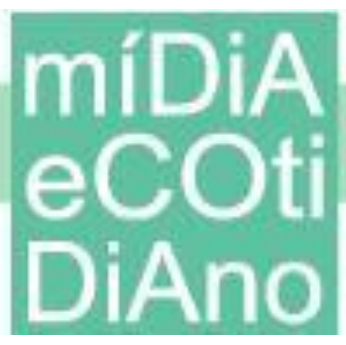

atenção redobrada. Em primeiro lugar, articula contraditoriamente dois aspectos: trata-se de matéria morta, queratina; por outro lado cresce continuadamente, parecendo estar vivo (AUZÉPY, 2011, p.7). Junto com outros aspectos, é visto como um signo que traduziria a personalidade. Não ter os cabelos tratados ou arrumados, operaria como um sinal moral de uma pessoa desleixada ou até suja. Na publicidade de Salon Line o cabelo encarna mais do que qualquer outro atributo a identidade de si. Evidentemente, pele, dentes, sobrancelhas, lábios articulam-se para compor a identidade pessoal - e Simmel (2007) explorou significativamente esses aspectos ao discutir o rosto como um conjunto organizado capaz de expressar valores, desejos, pensamentos.

Simbolicamente, uma importante operação semiótica se monta entre sujeito e cosmético: a utilização de cremes, shampoos ou condicionadores extrairia das profundezas do sujeito o seu verdadeiro eu. O poder dos cosméticos não estaria em sua capacidade de tornar a mulher mais bela, algo que ela já é, independentemente de seu aspecto físico, mas sim, o de revelar sua beleza interior não percebida ou identificada em função das influências sociais que mascaram seu eu. No site de Salon Line ${ }^{9}$ há todo um conjunto de ideias ou de discursos acerca das transformações capilares disponíveis para as clientes.

O uso dos produtos Salon Line articularia, então, um duplo processo de identificação e subjetivação: ao remover simbolicamente tudo aquilo que impede o sujeito de identificar-se consigo mesmo (as referências exteriores), possibilitaria um alinhamento entre a nova imagem externa e a interna. Esse aspecto é posto em evidência na análise de Heilbrunn: "Quando compra produtos, o indivíduo pode alternativamente fazer referência à imagem real ou ideal que tem de si mesmo por meio de um fenômeno de congruência de imagem que postula que os indivíduos têm tendência a se portar em direção a produtos cuja imagem é conforme aquela que eles têm deles mesmos" (2005, p.97).

A identidade não é um dado estável a priori. Trata-se de um processo referencial que se constrói por meio de interações. Partindo dessa ideia, Heilbrunn indica que "podemos considerar que as práticas de consumo colocam em jogo um conjunto de interações que são como um teatro no qual o indivíduo se representa. A identidade corresponde nesse caso a uma apresentação de si nas interações" (2005, p.96). A

\footnotetext{
${ }^{9}$ Site da marca. Disponível em: https://salonline.com.br/. Consulta em 26/03/2020.
} 


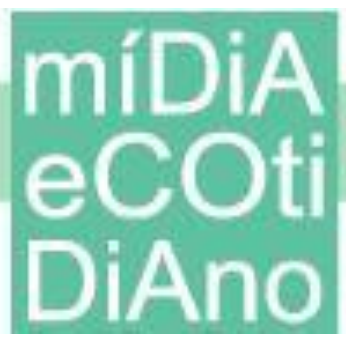

construção da identidade é um processo que articula diferentes referências, a imagem que temos de nós mesmos, a imagem que pensamos que os outros têm de nós, a imagem ideal e a imagem real.

"Transforme-se em você" é um processo que faz coincidir o eu interior com sua nova aparência. Trata-se de uma busca. A aparência possibilitada pelo uso dos cosméticos Salon Line não necessariamente torna a pessoa mais bela ou atraente. Não se trata disso. Os cosméticos removem exteriormente as camadas de anos e anos de produtos e tratamentos que escondiam o sujeito e paralelamente também extraem esse verdadeiro eu, fazendo-o emergir.

Há, contraditoriamente, uma crítica no discurso de Salon Line referente aos valores estéticos impostos pelos modelos normativos existentes na sociedade e veiculados pela mídia. Ser bela não necessariamente é adotar os padrões e modelos de beleza veiculados pela mídia e por outras empresas de cosméticos. Ser bela ou belo implica aceitar-se como se é - depois de um percurso de autodescoberta. O que Salon Line não diz é que seu próprio discurso encerra um modelo - que opera sugerindo a suas clientes não impor nenhum modelo.

Fiel escudeira, incansável zeladora da pessoa, Salon Line coloca-se ao lado da consumidora em sua jornada em busca de sua beleza interior: "Valorizando todas as belezas, a Salon Line sabe que cada pessoa, cada textura de cabelo e cada tipo de pele precisa de um cuidado específico, porque cada pessoa é única. Estamos sempre procurando entender o que você busca quando o assunto é se transformar na versão mais linda de si e é por isso que sempre estamos pertinho de você. Transforme-se em você com a Salon Line!"10. A fala anterior, publicada no site de Salon Line, assinala dois importantes princípios do individualismo e da subjetivação. No primeiro deles o discurso da empresa reforça a ideia de que cada pessoa é singular, o que exclui qualquer comparação. No segundo, o foco recai sobre as escolhas que o sujeito pode fazer ao eleger a "versão mais linda de si".

Nessa perspectiva, adotar um estilo que o singularize e o distinga dos demais indivíduos depende fundamentalmente da internalização da norma, de sua subjetivação.

\footnotetext{
${ }^{10}$ Site da marca. Disponível em: https://salonline.com.br/. Consulta em 26/03/2020.
} 


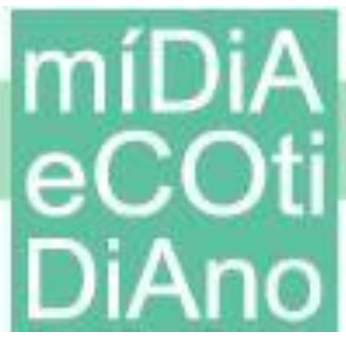

Subjetivada, a norma aparece como uma experiência pessoal, única e exclusiva para o sujeito. A adoção de um estilo que reforce a individualidade não equivale a dizer que o sujeito é autônomo, pois como assinalamos, a interiorização da norma social não torna o sujeito menos devedor de forças sociais. O detalhe é que o social na modernidade individualiza-se e subjetiva-se. Durkheim (1975) já discutia com propriedade a valorização do individualismo moral ao notar que nas sociedades modernas o indivíduo é ao mesmo tempo o Deus e seu fiel.

A internalização da norma e sua vivência como experiência pessoal implicam a responsabilização do sujeito pelos efeitos de suas escolhas. Como destaca Vigarello, "tudo muda ainda mais quando essa transformação depende exclusivamente da responsabilidade de cada um, engajando profundamente o desafio de identidade. $\mathrm{O}$ fracasso ganha, então, outro sentido, até a culpabilização ou a vitimização" (2007, p.250). Inseridas em um mundo onde nada mais pessoal do que escolher, afinal, escolher é necessário, a responsabilização e a culpabilização dos indivíduos por suas escolhas revelam um lado dramático da identidade que se subjetiva (QUEVAL, 2008).

\section{Considerações finais}

O exame do material visual e textual da campanha publicitária de Salon Line para produtos para cabelos leva a refletir sobre os desafios dos processos de individualização e de subjetivação. Conforme a narrativa veiculada pelo conjunto de materiais estudados, transformar-se em si mesma implica um reconhecimento de si pelo próprio sujeito. Trata-se de uma dobradura do sujeito sobre si próprio, como assinala Queval (2008).

Ao mesmo tempo em que impulsiona as consumidoras de seus cosméticos a transformarem-se em si mesmas, Salon Line opera um duplo processo de exclusão e identificação. Transformar-se em si mesma implica que se rompam as identificações com padrões veiculados pela mídia e que o sujeito se identifique consigo mesmo.

Assim, o papel dos cosméticos de Salon Line não é o de simplesmente transformar o cabelo das mulheres de acordo com a imagem ideal que os outros têm delas. Ao contrário, trata-se de apagar gradativamente as marcas impressas por modelos exteriores e anteriores que impediriam o "verdadeiro eu" de se expressar. O uso e a 


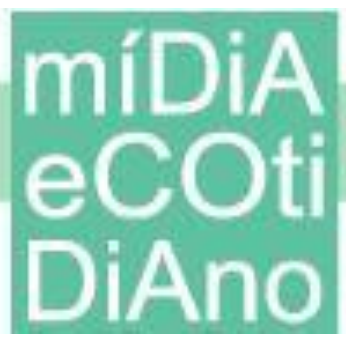

incorporação das supostas qualidades regeneradoras dos cosméticos fariam com que a consumidora se voltasse sobre ela mesma - daí a ideia de transformar-se não no outro ou na imagem que o outro teria dela. Ao valorizar o cabelo liso, crespo, crespíssimo, ondulado ou cacheado, os cosméticos Salon Line permitem que a usuária promova toda sua autonomia elegendo um estilo que seria único e exclusivamente seu. Não se trata de um processo imediato ou instantâneo, mas de um processo que pode ser mais ou menos longo e que variaria em função de sua autodescoberta.

Destaque-se o espaço não explícito verbalmente, mas observável visualmente, de destaque da mulher negra ou de alguma ascendência negra nas imagens de divulgação dos produtos da marca. Em Salon Line, a mulher negra ganha visibilidade. Sua beleza é valorizada, suas singularidades são exaltadas, embora, por vezes, com certa ambiguidade. Nas embalagens da linha "SOS Cachos", por exemplo, é uma modelo negra, de pele clara, com exuberante cabeleira no estilo black power que ilustra os produtos. Há, então, uma ambiguidade, que pode ser entendida como um cuidado, na construção das categorias cacheados e crespos, a segunda classificação carregando, por vezes, uma conotação menos positiva que a primeira. De todo modo, a marca dá visibilidade à mulher negra de uma forma positiva, associando-a a um modelo (mesmo que midiático) de beleza.

$\mathrm{Na}$ contemporaneidade, mais do que em qualquer outra época, o corpo ganha importância no processo de construção da individualidade e da subjetividade - no cotidiano como nas narrativas midiatizadas. Os cosméticos oferecem a possibilidade de transformar o corpo externamente e a subjetividade internamente. A incorporação gradual das qualidades dos cosméticos se daria mediante o consumo, importante mediador no processo de subjetivação. A fabricação da individualidade - já apontada desde os estudos de Simmel sobre a metrópole (2007) - ganha um novo impulso com a enorme oferta de produtos de embelezamento, assim como de referências disponíveis principalmente nas redes sociotécnicas ou nas mídias sociais, o que assinala a importância do processo de midiatização (KELLNER, 2001).

O consumo aparece como esfera mais do que central nesse processo. O poder da mídia deve, contudo, ser relativizado, uma vez que não se trata de tomar os sujeitos como pessoas passivas e que obedeceriam cegamente a ditames do mercado dos cosméticos. A norma ou a regra social, multiplicada e amplificada, não desaparece senão interioriza-se, 


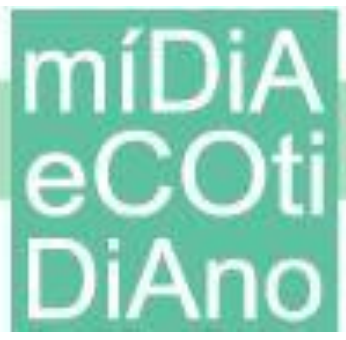

fazendo do sujeito o promotor de sua própria transformação e, ao mesmo tempo, assinalando sua responsabilidade nesse processo. Como enfatiza Vigarello, não se trata mais de ordenar o que consumir, mas principalmente de sugerir, papel ocupado com maestria por celebridades ou digital influencers.

Finalmente, mais do que apontar para um processo que libertaria o sujeito de forças e modelos sociais constrangedores, internalizam-se regras e normas. Cabe agora à própria mulher navegar por entre vozes e referências cada vez mais numerosas assim como arcar com as responsabilidades pelos erros e acertos no uso de produtos e tratamentos empregados no embelezamento de seu corpo e de seus cabelos. Desse modo, pode-se entender o quão estamos longe de uma visão romântica em que o indivíduo é senhor de seu próprio corpo e de seu destino. As narrativas publicitárias de individualização carregam na realidade forte aspecto social.

\section{Referências}

AUZÉPY, Marie-France. Le poil, signe ou symptôme ? In : AUZÉPY, Marie-France ;

CORNETTE, Joël (orgs). Histoire du poil. Paris: Belin, 2011. p. 5-26.

BARBOSA, Lívia. Marketing etnográfico. RAE - Revista de Administração, v.2, n.2, mai./jul/2003, p.39-43.

BROMBERGER, Christian. Les sens du poil : une anthropologie de la pilosité. Paris: Creaphis, 2016.

CARNEIRO, Sueli. Mulheres em movimento. Revista Estudos Avançados, n.17, v.49, São Paulo, set-dez 2003. p. 117 - 131.

DETREZ, Christine. La construction sociale du corps. Paris: Seuil, 2002.

DUMONT, Louis. O individualismo: uma perspectiva antropológica da ideologia moderna. Rio de Janeiro: Rocco, 1993.

DURKHEIM, Emile. O individualismo e os intelectuais. In: DURKHEIM, Emile. A ciência social e a acção. Lisboa: Bertrand, 1975. p.235-249.

DURKHEIM, Emile. As regras elementares da vida religiosa. São Paulo: Martins Fontes, 1996.

FOUCAULT, Michel. Histoire de la sexualité. 1. La volonté de savoir. Paris: Gallimard, 1976.

GEERTZ, Clifford. A interpretação das culturas. Rio de Janeiro: Zahar, 1978.

HEILBRUNN, Benoît. La consommation et ses sociologies. Paris: Armand Colin, 2005. 
KELLNER, Douglas. A cultura das mídias. Bauru, EDUSC, 2001.

LANOË, Catherine. Les systèmes de parures comme langage technique. Artefact: techniques, histoire et sciences humaines, n.1, Paris, CNRS, 2013, p.13-33.

LE BRETON, David. La sociologie du corps. Paris: PUF, 2010.

LE BRETON, David. Les passions ordinaires: anthropologie des émotions. Paris: Armand Colin, 2001.

LÉVI-STRAUSS, Claude. O pensamento selvagem. Campinas: Papirus, 1989.

LYOTARD, Jean-François. La condition postmoderne. Paris: Les éditions de Minuit, 2005.

MARZANO, Michela. Penser les corps. Paris: PUF, 2012.

MARZANO, Michela. La philosophie du corps. Paris : PUF, 2010.

MINAYO, Maria Cecília de Souza. O desafio do conhecimento: pesquisa qualitativa em saúde. São Paulo: Hucitec-Abrasco, 1992.

PERROT, Philippe. Le travail des apparences : le corps féminin. XVIIIe-XIXe siècle. Paris : Seuil, 1991.

QUEVAL, Isabelle. Le corps aujourd'hui. Paris: Gallimard, 2008.

ROCHA, Everardo. Magia e capitalismo: um estudo antropológico da publicidade. São Paulo: Brasiliense, 1985.

ROCHA, Everardo. Totemismo e mercado: notas para uma antropologia do consumo. Logos, ano 3, n.5, 2. ${ }^{\circ}$ Semestre/1996. p.55-57.

SIMMEL, G. Les grandes villes et la vie de l'esprit. Paris: L'Herne, 2007.

SIQUEIRA, Denise da Costa Oliveira; RIBEIRO, Vanessa. Hope ensina e reforça representações: estratégias da publicidade para o corpo feminino. Revista de Estudos de Comunicação, Curitiba, v.13, n. 32, p. 181-188, set./dez. 2012.

SIQUEIRA, Euler David. A natureza cultural do bronzeamento natural: midiatização, corpo e saber biomédico. In: SIQUEIRA, Denise da Costa Oliveira; FORTUNA, Daniele Ribeiro (orgs). Narrativas do eu: gênero, emoções e produção de sentidos. Porto Alegre: Sulina, 2019. p. 228245.

VIGARELLO, Georges. Histoire de la beauté : le corps et l'art d'embellir de la Renaissance à nos jours. Paris: Seuil, 2007. 